\title{
Clinical Features of Asymptomatic SARS-CoV-2 Infection in Hemodialysis Patients
}

\author{
Maria Soledad Pizarro-Sánchez ${ }^{a} \quad$ Alejandro Avello $^{b}$ Sebastian Mas-Fontao ${ }^{c}$ \\ Teresa Stock da Cunha ${ }^{b}$ Elena Goma-Garcés ${ }^{b}$ Mónica Pereira ${ }^{d} \quad$ Alberto Ortíz $^{\text {b, e }}$ \\ Emilio González-Parrab, e \\ ${ }^{a}$ Nephrology and Hypertension, Rey Juan Carlos Hospital, Madrid, Spain; ${ }^{b}$ Nephrology and Hypertension, \\ UH-Fundacion Jimenez Diaz UAM, Madrid, Spain; ${ }^{\circ}$ Renal Pathology and Diabetes Laboratory, IIS-FJD/CIBERDEM, \\ Madrid, Spain; 'Iñígo Álvarez de Toledo Renal Foundation (FRIAT), Madrid, Spain; ${ }^{e}$ Autónoma University of \\ Madrid, Madrid, Spain
}

\section{Keywords}

COVID-19 · Hemodialysis · Chronic kidney disease ·

Mortality · Asymptomatic

\begin{abstract}
Background: CKD is a risk factor for severe COVID-19. However, the clinical spectrum of COVID-19 in hemodialysis patients is still poorly characterized. Objective: To analyze the clinical spectrum of COVID-19 on hemodialysis patients. Method: A retrospective observational study was conducted on 66 hemodialysis patients. Nasopharyngeal swab PCR and serology for SARS-CoV-2, blood analysis, chest radiography, treatment, and outcomes were assessed. Results: COVID-19 was diagnosed in 50 patients: 38 (76\%) were PCR-positive and 12 (24\%) were PCR-negative but developed anti-SARSCoV-2 antibodies. By contrast, $17 \%$ of PCR-positive patients failed to develop detectable antibodies against SARS-CoV-2. Among PCR-positive patients, 5/38 (13\%) were asymptomatic, while among PCR-negative patients $7 / 12(58 \%)$ were asymptomatic $(p=0.005)$ for a total of $12 / 50(24 \%)$ asymptomatic patients. No other differences were found between PCR-
\end{abstract}

karger@karger.com www.karger.com/kbr

Karger"

BOPEN ACCESS
(C) 2021 The Author(s)

Published by S. Karger AG, Basel

This is an Open Access article licensed under the Creative Commons Attribution-NonCommercial-4.0 International License (CC BY-NC) (http://www.karger.com/Services/OpenAccessLicense), applicable to the online version of the article only. Usage and distribution for commercial purposes requires written permission. positive and PCR-negative patients. No differences in potential predisposing factors were found between asymptomatic and symptomatic patients except for a lower use of ACE inhibitors among asymptomatic patients. Asymptomatic patients had laboratory evidence of milder disease such as higher lymphocyte counts and oxygen saturation and lower troponin I and interleukin-6 levels than symptomatic patients. Overall mortality was $7 / 50(14 \%)$ and occurred only in symptomatic PCR-positive patients in whom mortality was 7/33 (21\%). Conclusions: Asymptomatic SARS-CoV-2 infection is common in hemodialysis patients, especially among patients with initial negative PCR that later seroconvert. Thus COVID-19 mortality in hemodialysis patients may be lower than previously estimated based on PCR tests alone.

(c) 2021 The Author(s)

Published by S. Karger AG, Basel

\section{Introduction}

The outbreak of SARS-CoV-2 starting in Wuhan in December 2019 has already spread to more than 100 countries worldwide. The cumulative number of con- 
firmed cases as of October 18,2020 , is over 40 million and there have been more than 1 million deaths worldwide.

CKD is a relevant comorbidity. Thus, hemodialysis patients have a higher mortality from any cause than the general population. The leading cause of death is cardiovascular disease, followed by infections $[1,2]$. Lung infections are the most common infectious cause of death in hemodialysis patients [3]. Regarding COVID-19, hemodialysis patients may be at higher risk of infection because of healthcare system frequentation and the need to go to the dialysis centers an average of 3 times a week. The risk is enhanced by communal transport to dialysis units. Once infected, the altered innate and adaptive immunity in uremia and frequent comorbidities, such as diabetes and cardiovascular disease, may further increase the risk of severe infection [4]. Additionally, infections and mortality from cardiovascular causes are interrelated, so that death from cardiovascular causes increases significantly after the diagnosis of infections, especially respiratory infections, more markedly in the early days of infection in both the general population and in dialysis patients [5]. Nephrology Societies [6] have developed guidelines for prevention, mitigation, and containment of COVID-19 in hemodialysis centers. Recommendations are generally based on preventing contagion and early detection of SARS-CoV-2 infection based on symptoms. COVID-19 symptoms appear after an incubation period of approximately 5.2 days [7]. The most common symptoms ones at the onset of the disease are fever, cough, and dyspnea. However, the clinical presentation is very varied and some patients develop more severe disease with pneumonia and acute respiratory distress syndrome [8]. Asymptomatic transmission of SARS-CoV-2 is an important issue in the control of this pandemic as it appears to be a major source of contagion. Indeed, SARS-CoV-2 can be detected in nasopharyngeal swabs up to 6 days prior to the development of symptoms [9]. Additionally, between 18 and $30 \%$ and up to $80 \%$ of SARS-CoV-2 may be asymptomatic, with different numbers coming from different epidemiological backgrounds [10-12]. Asymptomatic carriers may also transmit the disease [13].

The current understanding of the impact of dialysis severity of COVID-19 is mainly based on reports on PCR diagnosis of COVID-19. We now report the clinical features of asymptomatic and symptomatic hemodialysis patients as well as COVID-19 hemodialysis patients with positive and negative nasopharyngeal swab PCR results.

Asymptomatic COVID-19 in

Hemodialysis

\section{Materials and Methods}

This was a retrospective observational study of COVID-19 in chronic hemodialysis patients from the Hemodialysis Unit of the University Hospital Fundación Jiménez Diaz (UHFJD), Madrid, Spain and its associated dialysis center. This study was approved by the IIS-Fundación Jiménez Díaz Ethics Committee (PIOH03620_FJD) and was performed in accordance with the Declaration of Helsinki and the European Union Clinical Trial Directive. Patients were enrolled after providing written informed consent. This is a further analysis of a prior database [14], focusing on the clinical characteristics of COVID-19 in hemodialysis patients, with emphasis on the differences between symptomatic and asymptomatic patients as well as between patients that were diagnosed based on positive nasopharyngeal swab PCR test and those negative for the PCR analysis and diagnosed based on the development of antiSARS-CoV-2 antibodies. In addition to the different analysis approach, the database for the present study was locked 1 month later the prior one, and by that time, 2, further, COVID-19 patients had been diagnosed. In both units, respiratory droplet isolation measures were initiated on February 24, 2020.

In March 2020, the Hemodialysis Unit at UHFJD cared for 58 patients in the chronic hemodialysis program and the Fundación Renal Centro Santa Engracia for 142 patients (200 patients in total with age $>18$ years). Initially, patients in both units suspected of having an infection, that is, who presented clinical symptoms compatible with COVID-19 or close contact with symptomatic individuals, were tested for SARS-CoV-2 by nasopharyngeal swab PCR. Patients with positive results were transferred to the UHFJD hemodialysis unit. Eventually, only 5 patients on dialysis at UHFJD had not being tested. Thus, they were offered testing because of their inhospital location despite not having symptoms nor close contact with infected individuals beyond attendance to the same dialysis unit (Fig. 1). At the time, the peak of the pandemic, PCR testing was in short supply, and indications were closely monitored. A total of 66 patients, of which 38 belonged to UHFJD and 28 to Fundación Renal Centro Santa Engracia, were tested for SARS-CoV-2 by PCR. Nucleic acids extracted from nasopharyngeal swab samples were amplified by qPCR using the ORF1ab and $\mathrm{N}$ genes as targets. Patients were considered PCR negative when the test had been negative at least twice. The time between 2 negative PCR assessments was 14 days. Serological tests (IgM/IgG) were also performed using ELISA (VIRCELL, Granada, Spain). Sensitivity for this test was IgG 100\% (19 days after PCR+), IgM 82-88\% (7 days after PCR+), and specificity IgG 98\%, IgM 98.8\%.

Routine lab tests for patients with suspected COVID-19 were also performed including blood count with lymphocyte quantification, general biochemistry, and parameters related to inflammation (ferritin, D-dimer [DD], KL6 glycoprotein, and interleukin-6 [IL6]), and myocardial damage (troponin I [TnI]). Oxygen saturation was assessed, and chest X-ray was also performed. Only COVID-19 patients who were PCR positive were dialyzed in isolation. Those diagnosed by the presence of antibodies were dialyzed in the general dialysis room.

\section{Prevention and Treatment}

Droplet respiratory protection measures with a surgical mask for both patients and staff, hand washing, and other isolation measures were initiated on February 24, 2020, 2 weeks before the first COVID-19 patient was diagnosed. Admission criteria were based

Kidney Blood Press Res 2021;46:126-134 127 


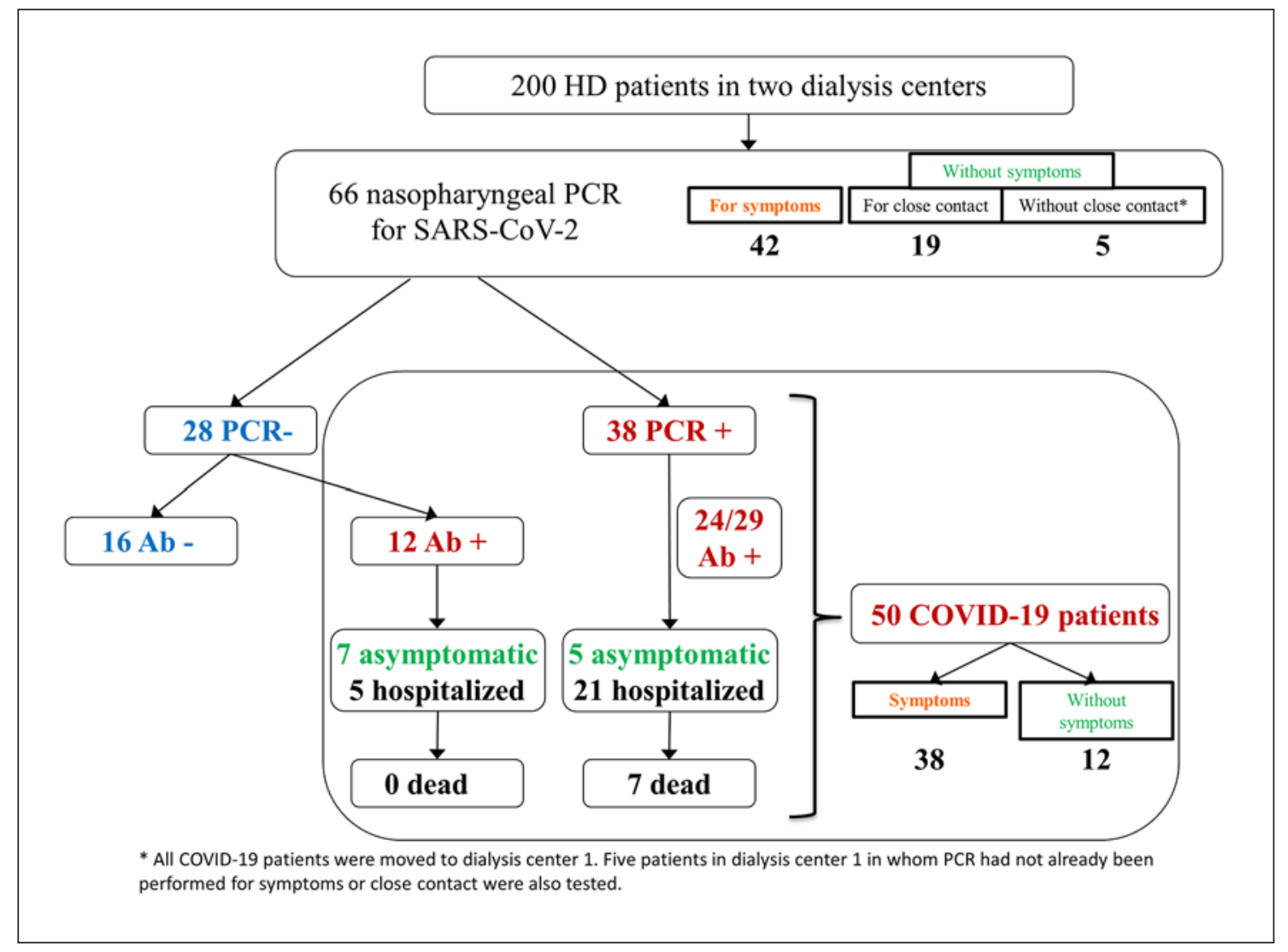

Fig. 1. Flow chart of the total population studied.

on the presence of pneumonia, oxygen saturation below $94 \%$ (or hypoxemia evidenced in arterial blood), and/or significant deterioration in general condition. Initial treatment for all admitted patients and outpatients was according to the weekly updated protocol of the UHFJD at the time. Treatment consisted of hydroxychloroquine ( $200 \mathrm{mg} / 12 \mathrm{~h}$ for 5 days) and antibiotics (doxycycline $100 \mathrm{mg} / 12 \mathrm{~h}$ for 5 days or levofloxacin $250 \mathrm{mg} / 48 \mathrm{~h}$ for 5 days). In case of acute respiratory insufficiency and inflammatory signs, such as marked elevation of ferritin and C-reactive protein, glucocorticoids were added $(250 \mathrm{mg}$ /day Methylprednisolone for 3 days, followed by oral prednisone $40 \mathrm{mg}$ every $12 \mathrm{~h}$ for 3-4 days). Prophylactic tinzaparin (3,500 IU/day) was added to those with analytical data of procoagulant status, that is, D-dimer elevation or markers of acute myocardial damage. For bilateral pneumonia and/or oxygen saturation below 94\%, lopinavir-ritonavir (Kaletra $400 \mathrm{mg} / 12 \mathrm{~h}$ for 5 days) was added, and finally, in the most severe cases, tocilizumab $400 \mathrm{mg}$ (maximum 2 doses in $48 \mathrm{~h}$ ) was added if oxygen requirement was between 10 and $15 \mathrm{~L} / \mathrm{min}$. Oxygen therapy was initiated when oxygen fell below 93\%. The most severe cases were admitted to the ICU. Hemodialysis was performed in an independent isolation room for PCR-positive cases. No changes in usual dialysis treatment were done.

\section{Statistical Analysis}

Quantitative variables were described by the mean and standard deviation or by the median and range depending if data are normally distributed. Qualitative variables were described by absolute and relative frequencies. For quantitative variables to compare groups, the Student's $t$, Mann-Whitney, ANOVA, and Kruskal-Wallis tests were employed depending on the number of variables compared and Shapiro-Wilk normality and Fisher's exact independence tests were employed for qualitative variables. The calculations were made in $\mathrm{R}$ version 4.0 (https://cran.r-project. $\operatorname{org} /)$.

\section{Results}

Diagnosis of COVID-19

Out of 200 hemodialysis patients, 66 patients were tested for SARS-CoV-2 by PCR or by detection of IgG and IgM antibodies to SARS-CoV-2 (Fig. 1). Of the 66 patients, 38 were PCR positive and 28 were PCR negative. Of the PCR-negative patients, $12 / 28$ patients were diagnosed of COVID-19 based on the development of antiSARS-CoV-2 antibodies for a total of 50 COVID-19 patients. 
Table 1. Clinical characteristics and outcomes for all COVID-19 patients, diagnosed either by PCR or antibody positivity

\begin{tabular}{|c|c|c|c|c|}
\hline$N$ & $\begin{array}{l}\text { All } \\
50\end{array}$ & $\begin{array}{l}\text { Asymptomatic } \\
12\end{array}$ & $\begin{array}{l}\text { Symptomatic } \\
38\end{array}$ & $p$ value \\
\hline Age, years & $71.7 \pm 12.5$ & $67.3 \pm 12.3$ & $73.1 \pm 12.4$ & ns \\
\hline Female, \% & $16(32)$ & $5(41.7)$ & $11(28.9)$ & ns \\
\hline BMI, $\mathrm{kg} / \mathrm{m}^{2}$ & $24.7 \pm 4.5$ & $24.7 \pm 4$ & $24.6 \pm 4.8$ & ns \\
\hline $\mathrm{DM}, n(\%)$ & $18(36)$ & $6(50)$ & $12(32)$ & ns \\
\hline Hypertension, $n(\%)$ & $46(92)$ & $12(100)$ & $34(89)$ & ns \\
\hline CVD, $n(\%)$ & $13(26)$ & $4(33)$ & $9(24)$ & ns \\
\hline ACEIs, $n(\%)$ & $10(20)$ & $0(0)$ & $10(26.3)$ & 0.047 \\
\hline ARBs, $n(\%)$ & $6(12)$ & $3(25)$ & $3(7.9$ & ns \\
\hline $25(\mathrm{OH})$ Vitamin $\mathrm{D}, \mathrm{ng} / \mathrm{mL}$ & $22.4 \pm 15.8$ & $19.9 \pm 9.1$ & $24 \pm 17.6$ & ns \\
\hline Lymphocyte count 3 mo ago, $/ \mu \mathrm{L}$ & $1,300 \pm 595.5$ & $1,120 \pm 396.2$ & $1,327.3 \pm 620.1$ & ns \\
\hline \multicolumn{5}{|l|}{ Clinical manifestations } \\
\hline Fever, $n(\%)$ & $16(32)$ & $0(0)$ & $16(42.1)$ & ns \\
\hline Dyspnea, $n(\%)$ & $4(8)$ & $0(0)$ & $4(10.5)$ & ns \\
\hline Pneumonia, $n(\%)$ & $27(54)$ & $1(8.3)$ & $26(68.4)$ & ns \\
\hline Oxygen saturation, $\%$ & $93.6 \pm 4.4$ & $97.2 \pm 2$ & $93.4 \pm 4.1$ & 0.024 \\
\hline \multicolumn{5}{|l|}{ Laboratory } \\
\hline Hemoglobin, g/dL & $11.3 \pm 1.6$ & $11.8 \pm 1.6$ & $11.1 \pm 1.6$ & ns \\
\hline Lymphocyte count at admission, $/ \mu \mathrm{L}$ & $800 \pm 458.5$ & $1,275 \pm 473.1$ & $661.1 \pm 345.8$ & $<0.001$ \\
\hline D-Dimer, $\mu \mathrm{g} / \mathrm{L}$ & $1,528.7 \pm 1,252.4$ & $1,383.4 \pm 965$ & $1,441.6 \pm 1,167.7$ & ns \\
\hline Ferritin, ng/mL & $1,078.4 \pm 1,289$ & $725.6 \pm 639.8$ & $1,189.1 \pm 1,461.9$ & ns \\
\hline Troponin I, ng/mL & $1.0225 \pm 5.773$ & $0.0297 \pm 0.0283$ & $1.3243 \pm 6.6361$ & 0.044 \\
\hline $\mathrm{KL} 6, \mathrm{U} / \mathrm{mL}$ & $321.1 \pm 143.8$ & na & $328.8 \pm 150.4$ & na \\
\hline IL6, pg/mL & $42.6 \pm 65.7$ & $11.5 \pm 9$ & $56.0 \pm 74.9$ & 0.03 \\
\hline \multicolumn{5}{|l|}{ Outcomes } \\
\hline Hospitalization, $n(\%)$ & $25(50)$ & $0(0)$ & $25(65.8)$ & $<0.001$ \\
\hline Death, $n(\%)$ & $7(14)$ & $0(0)$ & $7(18.4)$ & ns \\
\hline
\end{tabular}

For categorical data, the number of positive events observed, and the Fisher's exact test values are shown. ACEI, angiotensin conversion enzyme inhibitor; na, not available. CVD, past history of cardiovascular disease (stroke, myocardial infarction, or hospitalization for ischemic heart disease). $p$ value for the comparison of asymptomatic versus symptomatic patients. Values in bold are statistically significant.

\section{Presence of Symptoms and Outcomes in COVID-19}

\section{Patients}

Of the 50 patients with COVID-19, 12 (24\%) were asymptomatic. Asymptomatic PCR-positive patients represented 5/38 (13\%) PCR-positive patients, and asymptomatic PCR-negative patients represented 7/12 (58\%) PCR-negative COVID-19 patients $(p=0.005)$. At the end of follow-up, 7/50 (14\%) COVID-19 patients had died, 28 patients were cured (56\%), and $3 \mathrm{PCR}+$ patients continued infected. All patients who died were PCR+ and symptomatic; mortality in these symptomatic positive patients was $7 / 33(21 \%)$. Most deaths $(n=5)$ occurred early in the outbreak and could not be serologically tested.

Asymptomatic COVID-19 in

Hemodialysis

\section{Clinical Characteristics of Asymptomatic versus} Symptomatic COVID-19 Patients

We next analyzed clinical characteristics and outcomes for different subgroups of patients. No significant differences were found between symptomatic patients diagnosed by PCR (PCR positive) and by the presence of antibodies (PCR negative) or between asymptomatic patients diagnosed by PCR (PCR positive) and by the presence of antibodies (PCR negative) (see online suppl. Table 1; for all online suppl. material, see www.karger.com/ doi/10.1159/000512535). Thus, all asymptomatic COVID-19 patients $(n=12)$ were grouped together and compared with all symptomatic COVID-19 patients $(n=$ 38) (Table 1). The most frequent symptoms were dys- 
Table 2. Clinical characteristics and outcomes for PCR-positive patients: asymptomatic versus symptomatic individuals

\begin{tabular}{|c|c|c|c|c|}
\hline$N$ & $\begin{array}{l}\text { All } \\
38\end{array}$ & $\begin{array}{l}\text { Asymptomatic } \\
5\end{array}$ & $\begin{array}{l}\text { Symptomatic } \\
33\end{array}$ & $p$ value \\
\hline Age, years & $72.6 \pm 11.8$ & $65.6 \pm 10.7$ & $73.7 \pm 11.8$ & ns \\
\hline Female, \% & $12(31.6)$ & $2(40)$ & $10(30.3)$ & ns \\
\hline BMI, kg/m² & $24.4 \pm 4.7$ & $23.6 \pm 4.07$ & $24.5 \pm 4.88$ & ns \\
\hline ACEIs, $n(\%)$ & $9(24)$ & $0(0)$ & $9(27)$ & ns \\
\hline ARBs, $n(\%)$ & $5(13)$ & $2(40)$ & $3(9)$ & ns \\
\hline $25(\mathrm{OH})$ vitamin $\mathrm{D}, \mathrm{ng} / \mathrm{mL}$ & $22.5 \pm 17.1$ & $17.4 \pm 6.67$ & $23.3 \pm 18.1$ & ns \\
\hline Lymphocyte count 3 mo ago, $/ \mu \mathrm{L}$ & $1,283.8 \pm 595.1$ & $1,120 \pm 396$ & $1,309 \pm 621$ & ns \\
\hline Positive anti-SARS-CoV-2 antibodies, $n(\%)$ & $29(76.3)$ & $5(100)$ & $24(72.7)$ & ns \\
\hline \multicolumn{5}{|l|}{ Clinical manifestations } \\
\hline Fever, $n(\%)$ & $12(32)$ & $0(0)$ & $12(36)$ & ns \\
\hline Dyspnea, $n(\%)$ & $7(18)$ & $0(0)$ & $7(21)$ & ns \\
\hline Pneumonia, $n(\%)$ & $24(63)$ & $1(20)$ & $23(70)$ & 0.052 \\
\hline Oxygen saturation, $\%$ & $93.3 \pm 4.5$ & $97.3 \pm 2.4$ & $92.8 \pm 4.4$ & 0.037 \\
\hline \multicolumn{5}{|l|}{ Laboratory } \\
\hline Hemoglobin, g/dL & $11.3 \pm 1.47$ & $12.2 \pm 1.48$ & $11.2 \pm 1.43$ & 0.13 \\
\hline Lymphocyte count at admission, $/ \mu \mathrm{L}$ & $765.8 \pm 470$ & $1,460 \pm 643$ & $661 \pm 343$ & 0.003 \\
\hline D-Dimer, $\mu \mathrm{g} / \mathrm{L}$ & $1,483 \pm 1,301$ & $903 \pm 480$ & $1,580 \pm 1,373$ & ns \\
\hline Ferritin, ng/mL & $1,231.3 \pm 1,439$ & $918 \pm 888$ & $1,280 \pm 1,513$ & ns \\
\hline Troponin I, ng/mL & $1.3 \pm 6.6$ & $0.011 \pm 0.001$ & $1.47 \pm 6.94$ & 0.011 \\
\hline KL6, U/mL & $308 \pm 106$ & na & $308 \pm 107$ & na \\
\hline IL6, pg/mL & $43.6 \pm 65.7$ & $8.6 \pm 3.5$ & $50.3 \pm 70$ & ns \\
\hline \multicolumn{5}{|l|}{ Outcomes } \\
\hline Hospitalization, $n(\%)$ & $21(55)$ & $0(0)$ & $21(64)$ & 0.012 \\
\hline Death, $n(\%)$ & $7(18)$ & $0(0)$ & $7(21.2)$ & ns \\
\hline
\end{tabular}

For categorical data, the number of positive events observed, and the Fisher's exact test values are shown. na, not available; ACEI, angiotensin conversion enzyme inhibitor. $p$ value: for the comparison of asymptomatic versus symptomatic individuals among PCR+ patients. Values in bold are statistically significant.

pnea, fever, and diarrhea, with 26 having symptomatic pneumonia and 1 pneumonia case diagnosed in an asymptomatic patient (based on chest X-ray).

There were no differences between asymptomatic and symptomatic patients in baseline characteristics such as age, sex, BMI, lymphocyte counts, or $25 \mathrm{OH}$ vitamin $\mathrm{D}$ levels (Table 1) or comorbidities like diabetes, hypertension, or cardiovascular disease. Among asymptomatic patients, there was a lower prevalence of angiotensin conversion enzyme inhibitor prescription ( 0 vs. $10 \%$; $p=$ 0.047 ), without overall differences in RAS blockade. Interestingly, there was no difference in the development of anti-SARS-CoV-2 antibodies.

Asymptomatic patients had a significantly higher mean oxygen saturation $(97.2 \pm 2$ vs. $93.4 \pm 4.1 \%, p=$ 0.024 ) as well as milder laboratory markers of severity, such as significantly higher lymphocyte counts at admis- sion $(1,275 \pm 473$ vs. $661 \pm 346 / \mu \mathrm{L}, p<0.001)$, lower values of IL-6 (11.5 \pm 9 vs. $56.0 \pm 74.9 \mathrm{pg} / \mathrm{mL}, p=0.03)$, and TnI $(0.0297 \pm 0.0283$ vs. $1.3243 \pm 6.6361 \mathrm{ng} / \mathrm{mL}, p=0.044)$, representing markers of less severe inflammation and less cardiac damage, respectively. Additionally, asymptomatic patients were less frequently hospitalized ( 0 vs. $65.8 \%$, $p<0.001)$ and none of them died.

\section{Clinical Characteristics of Asymptomatic versus \\ Symptomatic PCR-Positive Patients}

Several COVID-19 patients were diagnosed retrospectively, based on the development of anti-SARS-CoV-2 antibodies. Thus, we next focused on a smaller population: the 38 patients that were diagnosed of COVID-19 based on a positive PCR test, of which 33 were symptomatic and 5 asymptomatic (Table 2). The most frequent symptoms were dyspnea, fever, and diarrhea, with 23 
Table 3. Clinical characteristics and outcomes for COVID-19 patients based on PCR results: PCR-positive versus PCR-negative patients

\begin{tabular}{|c|c|c|c|c|}
\hline$N$ & $\begin{array}{l}\text { All } \\
50\end{array}$ & $\begin{array}{l}\text { PCR+ } \\
38\end{array}$ & $\begin{array}{l}\text { PCR- } \\
12\end{array}$ & $p$ value \\
\hline Age, years & $71.7 \pm 12.5$ & $72.6 \pm 11.8$ & $68.6 \pm 14.5$ & ns \\
\hline Gender (female), \% & $16(32)$ & $12(31.6)$ & $4(33)$ & ns \\
\hline $\mathrm{BMI}, \mathrm{kg} / \mathrm{m}^{2}$ & $24.7 \pm 4.5$ & $24.4 \pm 4.7$ & $25.6 \pm 3.78$ & ns \\
\hline ACEIs, $n(\%)$ & $10(20)$ & $9(24)$ & $1(8.3)$ & ns \\
\hline ARBs, $n(\%)$ & $6(12)$ & $5(13)$ & $1(8.3)$ & ns \\
\hline $25(\mathrm{OH})$ vitamin $\mathrm{D}, \mathrm{ng} / \mathrm{mL}$ & $22.4 \pm 15.8$ & $22.5 \pm 17.1$ & $22 \pm 11.5$ & ns \\
\hline Lymphocyte count 3 mo ago, $/ \mu \mathrm{L}$ & $1,300 \pm 595.5$ & $1,283.8 \pm 595.1$ & $1,900 \pm \mathrm{NaN}$ & ns \\
\hline \multicolumn{5}{|l|}{ Clinical manifestations } \\
\hline Asymptomatic, \% & $12(24)$ & $5(13.2)$ & $7(58)$ & $0.001^{*}$ \\
\hline Fever & $16(32)$ & $12(32)$ & $4(33)$ & ns \\
\hline Dyspnea & $4(8)$ & $7(18)$ & 0 & ns \\
\hline Pneumonia, \% & $27(54)$ & $24(63)$ & $3(25)$ & ns \\
\hline Oxygen saturation, \% & $93.6 \pm 4.4$ & $93.3 \pm 4.5$ & $95.8 \pm 3.63$ & ns \\
\hline \multicolumn{5}{|l|}{ Laboratory } \\
\hline Hemoglobin, g/dL & $11.3 \pm 1.6$ & $11.3 \pm 1.47$ & $11.1 \pm 2.09$ & ns \\
\hline Lymphocyte count at admission, $/ \mu \mathrm{L}$ & $800 \pm 458.5$ & $765.8 \pm 470$ & $908 \pm 419$ & ns \\
\hline D-Dimer, $\mu \mathrm{g} / \mathrm{L}$ & $1,529 \pm 1,252$ & $1,483 \pm 1,301$ & $1,662 \pm 1,140$ & ns \\
\hline Ferritin, ng/mL & $1,078 \pm 1,289$ & $1,231 \pm 1,439$ & $696 \pm 717$ & ns \\
\hline Troponin I, ng/mL & $1.02 \pm 5.77$ & $1.3 \pm 6.6$ & $0.04 \pm 0.03$ & ns \\
\hline $\mathrm{KL} 6, \mathrm{U} / \mathrm{mL}$ & $321.1 \pm 143.8$ & $308 \pm 106$ & $373 \pm 316$ & ns \\
\hline IL6, pg/mL & $42.6 \pm 65.7$ & $43.6 \pm 65.7$ & $39.9 \pm 68.5$ & ns \\
\hline \multicolumn{5}{|l|}{ Outcomes } \\
\hline Hospitalization, $n(\%)$ & $25(50)$ & $21(55)$ & $4(33$ & ns \\
\hline Death, $n(\%)$ & $7(14)$ & $7(18)$ & $0(0)$ & ns \\
\hline
\end{tabular}

For categorical data, the number of positive events observed, and the Fisher's exact test values are shown. na, not available; ACEI, angiotensin conversion enzyme inhibitor. $p$ value: for the comparison of PCR-positive versus PCR-negative patients. Significant values are labeled with *.

having symptomatic pneumonia and one pneumonia case diagnosed in an asymptomatic patient. The PCRpositive population is of interest because they are usually diagnosed earlier than patients diagnosed based on the presence of antibodies. As it was a smaller population than the overall COVID-19 population, some of the significant differences were lost, despite persistence of the same trends. The 2 populations differed in a statistically significant manner in the higher lymphocyte counts $(1,460 \pm 643$ vs. $661 \pm 343, p=0.003)$ and oxygen saturation $(97.3 \pm 2.4$ vs. $92.8 \pm 4.4 \%, p=0.037)$ at admission and lower TnI values $(0.011 \pm 0.001$ vs. $1.47 \pm 6.94 \mathrm{ng} / \mathrm{mL}$, $p=0.011)$ in asymptomatic patients. None of the asymptomatic patients was hospitalized or died.

Serology was performed on 29 of the 38 PCR+ patients, of which $5(17.2 \%)$ were negative for IgG and IgM at a mean of 16.8 days of the diagnosis, while 24 (82.8\%) were positive for IgG and/or IgM: 2 were positive for IgG, 3 for IgM, and 19 for both. All patients not developing antibodies were symptomatic.

\section{Clinical Characteristics of PCR-Positive versus PCR-}

Negative COVID-19 Patients

A further analysis explored potential differences between PCR-positive versus PCR-negative COVID-19 patients (Table 3). This is relevant for clinical practice to define what set of patients may be missed by the initial diagnostic approach based on PCR. The main differences between PCR-positive and PCR-negative COVID-19 patients were the significantly higher frequency of symptoms among PCR+ patients than among PCR-patients ( 87 vs. $42 \%$ were symptomatic, $p=0.001$ ). There were no other significant differences between the groups. Interestingly, $25 \%$ of PCR-negative patients presented with 
pneumonia. Although numbers were too low to assess for statistically significant differences, all patients that died were PCR+.

\section{Discussion/Conclusion}

The main contributions of this study are to provide insights into the frequency and clinical characteristics and outcomes of asymptomatic hemodialysis patients infected by SARS-CoV-2. The frequency of asymptomatic SARS-CoV-2 infection is higher than expected from PCR studies and only becomes apparent by additionally assessing the development of an immune response against the virus. Asymptomatic patients have a better prognosis and their presence resulted in lower overall mortality estimates in dialysis patients with COVID-19. In addition, the analytical response shows that the absence of clinical signs is related to a very limited infectious and inflammatory response. On the contrary, symptomatic patients showed higher levels of IL6 and frequency of lymphopenia, thus a more severe inflammatory response, associated with a higher number of hospitalizations.

In our study, patients with either a PCR+ test or presence of anti-SARS-CoV-2 antibodies were diagnosed as COVID-19. The first question that arises is about the reliability of the diagnostic methods that allow the identification of infected patients. Nasopharyngeal swab PCR testing is marred by up to $30 \%$ of false-negative results and rarely by false-positive results $[15,16]$, potentially leading to misdiagnosis and misguided treatment. According to the diagnostic and treatment guidelines for COVID-19, if PCR is negative twice or more it should be considered truly negative [17], but some cured patients have subsequently become PCR positive again [18]. In addition, false-positive results have been observed due to contamination and other reasons [16]. Deletions and mutations in the SARSCoV-2 genome can also contribute to false-negative PCR results. Detection of anti-SARS-CoV-2 antibodies may be problematic and rapid tests that provide results in minutes from a blood drop have been reported unreliable quite frequently. ELISA is now highly recommended and was expected to improve the rate of detection of COVID-19 as antibodies allow a much longer window of detection than PCR. In addition, ELISA has a fast response time and relatively low costs $[15,16]$. One caveat is that some ELISA methods may generate false-positive results due to common human coronavirus proteins cross-reactivity [19].

In addition, we identified PCR + patients who did not develop antibodies. In the present series, $17 \%$ of hemodi- alysis patients did not develop antibodies during the follow-up period. The clinical consequences are poorly understood, but these patients may be prone to reinfection. In this regard, hemodialysis patients may not mount an adequate antibody response against some antigens. One example of clinical relevance is the hepatitis $B$ virus vaccine: special protocols are needed and even despite those, a significant proportion of patients do not develop adequate protective levels of anti-HBs antibodies [20].

Asymptomatic patients may be more frequent than previously thought [10]. It is difficult to estimate the prevalence without massive population testing. In some studies conducted in institutionalized populations, it is estimated to be between 18 and $30 \%$ [11, 12]. In a recent study, most people infected with SARS-CoV-2 showed no symptoms. Despite this, virus detection and isolation of carriers contributed to decrease the number of cases: the number of people with COVID-19 symptoms decreased by more than $90 \%$ in 10 days when people who were symptomatic and those who were asymptomatic were isolated [10]. Thus, the relevance of identifying asymptomatic patients lies in the ability of these patients to infect contacts [13]. In this regard, widespread screening of the population to isolate carriers may help to contain the pandemic [21]. In the only study so far, 15/90 (17\%) hemodialysis patients with positive PCR were asymptomatic, representing $40 \%$ of those infected [22]. Our data confirm the existence of asymptomatic infected hemodialysis patients and expand the clinical presentation range to PCR negative individuals.

The definition of an asymptomatic COVID-19 patient would include PCR+ without symptoms and also those who have seroconverted despite negative PCR results and absence of symptoms. In our study almost $25 \%$ of patients diagnosed of COVID-19 by either PCR or serology were asymptomatic, only $13 \%$ were asymptomatic if only PCR criteria were used to diagnose COVID-19. When comparing symptomatic with asymptomatic patients, asymptomatic patients also had milder analytical disease, characterized by a higher number of lymphocytes at diagnosis, lower levels of TnI and better oxygen saturation. This was also true when only PCR+ patients were analyzed, who would be expected to have higher viral load. However, despite absence of symptoms, asymptomatic patients may have underlying tissue injury. In a recent report, 24 of 25 asymptomatic patients had abnormal lung CT findings. While 16 recovered without symptoms, 9 developed a mild cough and/or other symptoms. Thus, one-third of initially asymptomatic patients with COVID-19 developed symptoms at follow-up and 
$>90 \%$ of these asymptomatic patients had abnormal lung CT findings at diagnosis [23]. Similar results have been reported by other authors [24]. In this regard, despite the lack of more sensitive lung CT scans, an asymptomatic patient in our series was found to have radiological pneumonia.

Regarding outcomes, asymptomatic patients did not require admission, and no deaths were recorded. Overall mortality was $14 \%$. However, it would have been $21 \%$ if only PCR+ patients were considered. Indeed, deaths were only noted among symptomatic PCR+ patients. In this regard, recent mortality data for COVID-19 patients in hemodialysis units have reported data only for PCR-positive patients. Thus, among 36 PCR-positive hemodialysis patients, mortality was 30\% [25] and increased to $61 \%$ for patients who required admission for hypoxia. The benign outcomes of asymptomatic patients suggest that their detection has mainly epidemiological interest to limit the spread of infection. In this regard, the fact that asymptomatic COVID-19 patients may also be PCR negative further supports the need for universal precautions independent of SARS-CoV-2 status.

Given than ACE2 is the receptor for SARS-CoV-2 entry into cells and that RAS blockade may modify ACE2 levels, there has been some controversy on the use of RAS blockers, with all scientific societies supporting their continued use in kidney and cardiovascular disease patients $[26,27]$. In our study, there are more patients receiving angiotensin conversion enzyme inhibitors in the symptomatic group, but the number of patients is low to draw definitive conclusions and overall use of RAS blockade did not differ between symptomatic and asymptomatic patients.

Among limitations, this study was retrospective and although one of the largest reported in the literature so far, it was still small in an absolute scale. However, despite this limitation, data in hemodialysis patients are consistent with those in the general population and suggest that the severity of COVID-19 among hemodialysis patients may have been overestimated and that systematic detection of asymptomatic patients would be required to stop transmission on SARS-CoV-2 in dialysis units themselves or events related to dialysis such as collective transport for patients, as well as for early treatment once this becomes available.

The incidence of COVID-19 among hemodialysis patients is higher than expected based on testing only by PCR and only those individuals that are symptomatic since there are PCR-negative patients that later develop antibodies against SARS-CoV-D-2 and because around
$24 \%$ of infected patients in dialysis units are asymptomatic. In this regard, reports of the high risk conferred by dialysis for severe COVID-19 causing death based on PCR diagnosis [28] should take into account the wider COVID-19 spectrum in these patients, including the potential negativity of PCR tests. While there was no mortality in asymptomatic patients in this study, they may be sources of disease transmission and any potential longterm consequences are unknown.

\section{Acknowledgements}

The authors would like to thank the members of the dialysis unit and in particular the nursing staff for their dedication and work in preventing the spread of the disease in our patients.

\section{Statement of Ethics}

This is an observational study that details the measures taken, medications, and analyses that have constituted the usual care in our unit during the COVID-19 epidemic. This study was approved by the IIS-Fundación Jiménez Díaz Ethics Committee (PIOH03620_FJD) and was performed in accordance with the Declaration of Helsinki and the European Union Clinical Trial Directive.

\section{Conflict of Interest Statement}

The authors have no conflicts of interest to declare.

\section{Funding Sources}

The Renal, Vascular, and Diabetes Laboratory is funded by Ministerio de Economia, Industria y Competitividad: research support from FIS ISCIII FEDER funds PI16/01298, PI15/00298, PI16/02057, PI16/01900, PI19/00815, DTS18/00032 ISCIII-RETIC REDinREN RD16/0009, CYTED IBERERC and Sociedad Madrileña de Nefrologia, ERA-PerMed-JTC2018 (KIDNEY ATTACK AC18/00064 and PERSTIGAN AC18/00071), and Comunidad de Madrid CIFRA2 B2017/BMD-3686.

\section{Author Contributions}

Conceptualization, E.G.P.; validation, S.P., T.S.C., E.G.G., A.A., and S.M.; formal analysis, S.M.; investigation, S.P., T.S.C., E.G.G., and A.A.; resources, M.P.; data curation, A.A. and S.M.; writing - original draft preparation, S.M. and E.G.P.; writing - review and editing, A.O.; supervision, E.G.P.; all authors have read and agreed to the published version of the manuscript. 


\section{References}

1 De Jager DJ, Grootendorst DC, Jager KJ, Van Dijk PC, Tomas LM, Ansell D, et al. Cardiovascular and noncardiovascular mortality among patients starting dialysis. JAMA. 2009; 302(16):1782-9.

2 Ortiz A, Covic A, Fliser D, Fouque D, Goldsmith D, Kanbay M, et al. Epidemiology, contributors to, and clinical trials of mortality risk in chronic kidney failure. Lancet. 2014; 383(9931):1831-43.

3 Sarnak MJ, Jaber BL. Pulmonary infectious mortality among patients with end-stage renal disease. Chest. 2001;120(6):1883-7.

4 Kato S, Chmielewski M, Honda H, PecoitsFilho R, Matsuo S, Yuzawa Y, et al. Aspects of immune dysfunction in end-stage renal disease. Clin J Am Soc Nephrol. 2008 Sep;3(5) 1526-33.

5 Smeeth L, Thomas SL, Hall AJ, Hubbard R, Farrington P, Vallance P. Risk of myocardial infarction and stroke after acute infection or vaccination. N Engl J Med. 2004 Dec;351(25): 2611-8.

6 Sánchez-Álvarez EJ, Fontán MP, Martín CJ, Pelícano MB, Reina CJC, Prieto ÁMS, et al. Situación de la infección por SARS-CoV-2 en pacientes en tratamiento renal sustitutivo Informe del Registro COVID-19 de la Sociedad Española de Nefrología (S.E.N.). Nefrología. 2020;40(3):272-8.

7 Wang W, Tang J, Wei F. Updated understanding of the outbreak of 2019 novel coronavirus (2019-nCoV) in Wuhan, China. J Med Virol. 2020 Apr;92(4):441-7.

8 Huang C, Wang Y, Li X, Ren L, Zhao J, Hu Y, et al. Clinical features of patients infected with 2019 novel coronavirus in Wuhan, China Lancet. 2020 Feb;395(10223):497-506.

9 Arons MM, Hatfield KM, Reddy SC, Kimball A, James A, Jacobs JR, et al. Presymptomatic SARS-CoV-2 infections and transmission in a skilled nursing facility. N Engl J Med. 2020 May 28;382(22):2081-90.
10 Day M. Covid-19: four fifths of cases are asymptomatic, China figures indicate. BMJ. 2020 Apr;369:m1375.

11 Mizumoto K, Kagaya K, Zarebski A, Chowell G. Estimating the asymptomatic proportion of coronavirus disease 2019 (COVID-19) cases on board the Diamond Princess cruise ship, Yokohama, Japan. Euro Surveill. 2020 Mar; 25(10):2000180.

12 Nishiura H, Kobayashi T, Miyama T, Suzuki A, Jung SM, Hayashi K, et al. Estimation of the asymptomatic ratio of novel coronavirus infections (COVID-19). Int J Infect Dis. 2020 May;94:154-5..mok

13 Bai Y, Yao L, Wei T, Tian F, Jin D-Y, Chen L, et al. Presumed asymptomatic carrier transmission of COVID-19. JAMA. 2020 Apr; 323(14):1406-7.

14 Stock da Cunha T, Gomá-Garcés E, Avello A Pereira-García M, Mas-Fontao S, Ortiz A, et al. The spectrum of clinical and serological features of COVID-19 in urban hemodialysis patients. JCM. 2020 Jul;9(7):2264.

15 Xiao SY, Wu Y, Liu H. Evolving status of the 2019 novel coronavirus infection: proposal of conventional serologic assays for disease diagnosis and infection monitoring. J Med Virol. 2020 May;92(5):464-7.

16 Wang M, Wu Q, Xu W, Qiao B, Wang J, Zheng $\mathrm{H}$, et al. Clinical diagnosis of 8274 samples with 2019-novel coronavirus in Wuhan. medRxiv. 2020 Feb.

17 Hong KH, Lee SW, Kim TS, Huh HJ, Lee J, Kim SY, et al. Guidelines for laboratory diagnosis of coronavirus disease 2019 (COVID-19) in Korea. Ann Lab Med. 2020 Sep; 40(5):351-60.

18 Lan L, Xu D, Ye G, Xia C, Wang S, Li Y, et al. Positive RT-PCR test results in patients recovered from COVID-19. JAMA. 2020 Apr; 323(15):1502-3.

19 Sun ZF, Meng XJ. Antigenic cross-reactivity between the nucleocapsid protein of severe acute respiratory syndrome (SARS) coronavirus and polyclonal antisera of antigenic group I animal coronaviruses: implication for SARS diagnosis. J Clin Microbiol. 2004 May;42(5): 2351-2.
20 Saco TV, Strauss AT, Ledford DK. Hepatitis $B$ vaccine nonresponders: possible mechanisms and solutions. Ann Allergy Asthma Immunol. 2018 Sep;121(3):320-7.

21 Lu S, Lin J, Zhang Z, Xiao L, Jiang Z, Chen J, et al. Alert for non-respiratory symptoms of Coronavirus Disease 2019 (COVID-19) patients in epidemic period: a case report of familial cluster with three asymptomatic COVID-19 patients. J Med Virol. 2020.

22 Albalate M, Arribas P, Torres E, Cintra M, Alcázar R, Puerta $\mathrm{M}$, et al. Alta prevalencia de covid19 asintomático en hemodiálisis. Aprendiendo dia a dia el primer mes de pandemia de covid19. Nefrología. 2020;40(3): 279-86.

23 An P, Song P, Wang Y, Liu B. Asymptomatic patients with Novel Coronavirus Disease (COVID-19). Balkan Med J. 2020 Jun 1;37(4): 229-30.

$24 \mathrm{Hu} \mathrm{Z}$, Song C, Xu C, Jin G, Chen Y, Xu X, et al. Clinical characteristics of 24 asymptomatic infections with COVID-19 screened among close contacts in Nanjing, China. Sci China Life Sci. 2020 May;63(5):706-11.

25 Goicoechea M, Sánchez Cámara LA, Macías N, Muñoz de Morales A, Rojas Á G, Bascuñana A, et al. COVID-19: clinical course and outcomes of 36 maintenance hemodialysis patients from a single center in Spain. Kidney Int. 2020;98(1):27-34.

26 South AM, Diz DI, Chappell MC. COVID-19, ACE2, and the cardiovascular consequences. Am J Physiol Heart Circ Physiol. 2020 May; 318(5):H1084-90.

27 Vaduganathan M, Vardeny O, Michel T, McMurray JJV, Pfeffer MA, Solomon SD. Reninangiotensin-aldosterone system inhibitors in patients with covid-19. N Engl J Med. 2020 Apr;382(17):1653-9.

28 Williamson EJ, Walker AJ, Bhaskaran K, Bacon S, Bates C, Morton CE, et al. Factors associated with COVID-19-related death using OpenSAFELY. Nature. 2020;584(7821):4306. 